\title{
Avaliação da poluição sonora no parque Jardim Botânico de Curitiba, Paraná, Brasil
}

\author{
Evaluation of noise pollution in the Botanical \\ Garden in Curitiba, Paraná, Brazil
}

Paulo Henrique Trombetta Zannin 1

Bani Szeremetta 1

\footnotetext{
1 Laboratório de Acústica Ambiental, Departamento de Engenharia Mecânica, Centro Politécnico, Universidade Federal do Paraná. C.P. 19011 , Curitiba, $P R$ 81531-990, Brasil zannin@demec.ufpr.br
}

\begin{abstract}
This study focuses on noise pollution in the Botanical Garden in Curitiba, Paraná, Brazil. Equivalent noise levels $\left(L_{e q}\right)$ were measured at 21 points throughout the park, and interviews were conducted with park visitors. Some $47.6 \%$ of the measurement sites presented $L_{\text {eq }}$ levels over $65 \mathrm{~dB}(A)$, considered by preventive medicine as the maximum tolerable exposure level without risk of health impairment, and $90.5 \%$ of the sites failed to comply with Municipal Ordinance 8,583, setting 55dB(A) as the maximum noise emission level for green areas. The results of interviews with visitors showed that 78\% visit the park at least twice a week and that 96\% come for physical activity. During their activities in the Botanical Garden, 24\% of interviewees identified noise pollution as a source of annoyance, as compared to $22 \%$ who complained of insufficient park security.
\end{abstract}

Key words Sound Contamination; Noise; Environmental Risks

Resumo Foi realizado um estudo da poluição sonora no parque Jardim Botânico de Curitiba. Efetuaram-se medições do nível sonoro equivalente $L_{\text {eq }}$ em $d B(A)$, em 21 pontos espalhados dentro da área do parque, além de entrevistas com os freqüentadores do local. Constatou-se que 47,6\% dos pontos de medição apresentaram níveis sonoros acima de $L_{e q}=65 d B(A)$, considerado pela medicina preventiva como o nível máximo a que um cidadão pode se expor sem riscos à saúde, e 90,5\% dos pontos avaliados não satisfizeram à Lei Municipal no 8.583, que fixa o limite de 55dB(A) como nível máximo de emissões sonoras em áreas verdes. O resultado do questionário aplicado na forma de entrevistas aos freqüentadores do parque mostrou que 78\% dos entrevistados costumam visitar o parque pelo menos duas vezes na semana e que $96 \%$ buscam a realização de uma atividade física. Durante a prática de suas atividades no parque, $24 \%$ dos entrevistados apontam a poluição sonora e $22 \%$ a segurança no local como fatores de perturbação.

Palavras-chave Poluição Sonora; Ruído; Riscos Ambientais 


\section{Introdução}

O ruído é um fato comum nos grandes centros urbanos, gerado principalmente pelos meios de transporte. Estudos mostram que o ruído de tráfego de $66 \mathrm{~dB}$ (A) é considerado como o limiar do dano à saúde e, conseqüentemente, a medicina preventiva estabelece $65 \mathrm{~dB}(\mathrm{~A})$ como o nível máximo a que um cidadão pode se expor no meio urbano, sem riscos (Belojevic et al., 1997; Maschke, 1999). Portanto, é preocupante que os níveis dos ruídos emitidos em vias com tráfego intenso atinjam normalmente $75 \mathrm{~dB}(\mathrm{~A})$ (Zannin et al., 2001, 2002).

Este trabalho justifica-se por ser o parque Jardim Botânico uma área de lazer que está localizada em uma região estritamente urbana de Curitiba, cercado por vias de intensa movimentação de veículos. Tais circunstâncias levantam duas hipóteses: violação da Lei Municipal no 8.583 (SMMA, 1995), que fixa o limite de $55 \mathrm{~dB}(\mathrm{~A})$ como nível sonoro máximo admissível para áreas verdes no período diurno (das 7 às 19 horas), e incômodo causado aos freqüentadores pelos níveis sonoros circunvizinhos ao parque. A fim de examinar as duas hipóteses, foram realizadas medições dos níveis sonoros em diferentes pontos do parque, além de entrevistas com os freqüentadores. Os níveis sonoros obtidos foram comparados com o nível de $65 \mathrm{~dB}(\mathrm{~A})$ e com a lei ambiental de Curitiba. As entrevistas serviram para avaliar como os freqüentadores percebem a problemática em questão, nos contextos geral e específico do parque.

\section{Materiais e métodos}

O parque Jardim Botânico possui uma área total de $270.000 \mathrm{~m}^{2}$, dos quais $40 \%$ correspondem a um remanescente de floresta de araucária. A pesquisa é do tipo descritiva, de acordo com seus objetivos, apontando características de um fenômeno: a influência do ruído urbano em uma área verde. Seu caráter ainda é exploratório, pois trata-se de um estudo-piloto sobre a exposição dos freqüentadores do parque aos ruídos.

Para a realização do trabalho de campo, foram necessárias duas fases: (1) medições dos níveis sonoros em diferentes pontos do parque, para compará-los com o nível de $65 \mathrm{~dB}(\mathrm{~A})$ e com a Lei Municipal no 8.583 (SMMA, 1995), que estabelece o nível de $55 \mathrm{~dB}$ (A) como limite máximo para emissões sonoras em Áreas Verdes; (2) utilização de um questionário elaborado pelos autores, aplicado por meio da técnica de entrevistas, com o objetivo de conhecer a reação dos freqüentadores do parque ao ruído ambiental.

A amostra de freqüentadores (52\% homens e $48 \%$ mulheres), num total de 50 , foi selecionada aleatoriamente. As faixas etárias foram classificadas da seguinte forma: de 19 a 29 anos (34\%); de 30 a 40 anos (26\%); de 41 a 51 anos (20\%); e acima de 52 anos (20\%). Os entrevistados foram abordados durante a realização de caminhadas e corridas. As entrevistas foram realizadas por dois entrevistadores, de segunda a sexta-feira, totalizando dez entrevistas por dia, no período das 18 às 19 horas, horário de maior utilização do parque.

O tamanho reduzido da amostra, de 50 entrevistados, deve-se à dificuldade encontrada em se obter a colaboração dos freqüentadores do parque para responder ao questionário. Essa dificuldade pode ser explicada pelo fato de as entrevistas terem sido efetuadas durante a realização dos exercícios e por tomarem um certo tempo das pessoas. Como posteriormente ficou evidente, $96 \%$ dos entrevistados procuram o parque para praticar atividades físicas. Onze pessoas recusaram-se a responder o questionário.

As medições foram efetuadas no horário de tráfego veicular mais intenso (das 18 às 19 horas), e com ausência de fontes sonoras atípicas: chuva e vento forte. As medições dos níveis sonoros foram realizadas com o medidor Brüel \& Kjaer 2238, de acordo com as seguintes etapas: (a) foram escolhidos 21 pontos de medição por meio da análise de carta topográfica; (b) as medições foram realizadas nas pistas por onde os freqüentadores do local circulam; (c) o tempo de medição em cada ponto foi de cinco minutos.

\section{Resultados e discussões}

Na Tabela 1 são apresentados os resultados das entrevistas realizadas com os freqüentadores do parque Jardim Botânico.

O parque Jardim Botânico apresentou elevados níveis sonoros, em sua maioria $(90,5 \%)$ acima do permitido pela Lei Municipal no 8.583, que estabelece o limite de $55 \mathrm{~dB}(\mathrm{~A})$ para áreas verdes. Somente $9,5 \%$ dos pontos satisfizeram à referida lei. Outra constatação decorrente das medições acústicas foi que $47,6 \%$ dos pontos apresentaram níveis sonoros superiores a $65 \mathrm{~dB}(\mathrm{~A})$, ou seja, acima do limite estabelecido pela medicina preventiva como o limiar do dano à saúde.

Apesar dos altos níveis de ruído, a maioria das pessoas (52\%) considerou o parque um lu- 
gar tranqüilo, que não provoca maiores perturbações, o que pode explicar a freqüência diária ao local. Dos entrevistados, $54 \%$ vão ao parque todos os dias, $24 \%$, três vezes por semana, $6 \%$, duas vezes por semana e $16 \%$, apenas uma vez por semana. Evidentemente, não se deve descartar a possibilidade de os freqüentadores já estarem acostumados ou adaptados ao ambiente. Além disso, a comparação do parque com outros locais do seu cotidiano, como o local de trabalho e o lugar onde moram, pode tê-los induzido a classificar o parque como mais tranqüilo (Tabela 1). Contudo, $24 \%$ das pessoas declararam sentir-se perturbadas pela poluição sonora e $22 \%$ pela preocupação com a segurança local (Tabela 1), o que permite concluir que esse tipo de poluição vem a ser mais incômoda do que outros agentes perturbadores no local.

\section{Considerações finais}

Com base nos resultados do diagnóstico da poluição sonora no Jardim Botânico, pode-se afirmar que a situação da área é preocupante, com elevados níveis de poluição sonora: $47,6 \%$ ultrapassam $65 \mathrm{~dB}(\mathrm{~A})$. Tais resultados mostram a evolução desse tipo de poluição em nosso meio, constituindo uma ameaça ao bem-estar e à saúde dos cidadãos em um dos poucos lugares da cidade capazes de oferecer alívio para as atribulações do cotidiano urbano. Enfatizando a grave situação da área, 90,5\% dos pontos medidos apresentaram níveis acima de $55 \mathrm{~dB}(\mathrm{~A})$, limite máximo para uma Área Verde segundo a legislação local. As entrevistas mostraram que a grande maioria dos freqüentadores $(96 \%)$ busca a realização de atividades físicas e que $78 \%$ visitam o Jardim Botânico pelo menos duas vezes na semana. Durante a prática de suas atividades no parque, $24 \%$ indicaram a poluição sonora e $22 \%$ a preocupação com a segurança no local como fatores de perturbação. No entanto, $52 \%$ dos entrevistados dizem não se sentir perturbados por nenhum fator ambiental ali presente.

\begin{tabular}{|c|c|c|}
\hline \multicolumn{3}{|l|}{ Questionário e resultados das entrevistas. } \\
\hline Perguntas/respostas & úmero total de entrevistados & $\%$ \\
\hline \multicolumn{3}{|l|}{$\begin{array}{l}\text { Com que freqüência você } \\
\text { costuma visitar o parque? }\end{array}$} \\
\hline Todos os dias & 27 & 54 \\
\hline 3 vezes por semana & 12 & 24 \\
\hline 2 vezes por semana & 3 & 6 \\
\hline 1 vez por semana & 8 & 16 \\
\hline \multicolumn{3}{|l|}{$\begin{array}{l}\text { Que tipo de atividade você } \\
\text { pratica no parque? }\end{array}$} \\
\hline Atividade física & 48 & 96 \\
\hline Relaxamento & 1 & 2 \\
\hline Meditação & 1 & 2 \\
\hline \multicolumn{3}{|l|}{$\begin{array}{l}\text { Durante a prática dessa atividade, } \\
\text { qual o fator no ambiente que lhe } \\
\text { causa maior perturbação? }\end{array}$} \\
\hline Preocupação com a segurança local & 11 & 22 \\
\hline Poluição sonora & 12 & 24 \\
\hline Poluição do ar & 1 & 2 \\
\hline Nenhum & 26 & 52 \\
\hline \multicolumn{3}{|l|}{$\begin{array}{l}\text { Você se sente afetado pelo } \\
\text { ruído gerado em torno do parque? } \\
\text { Como você classifica esse ruído? }\end{array}$} \\
\hline Sim (pouco intenso) & 10 & 20 \\
\hline Sim (intenso) & 5 & 10 \\
\hline Sim (muito intenso) & 5 & 10 \\
\hline Não & 30 & 60 \\
\hline \multicolumn{3}{|l|}{$\begin{array}{l}\text { No seu trabalho você se expõe } \\
\text { a ruídos intensos? Classifique-os. }\end{array}$} \\
\hline Sim (pouco intenso) & 4 & 8 \\
\hline Sim (intenso) & 3 & 6 \\
\hline Sim (muito intenso) & 8 & 16 \\
\hline Não & 35 & 70 \\
\hline \multicolumn{3}{|l|}{$\begin{array}{l}\text { Você se incomoda com os ruídos } \\
\text { na sua rua? Classifique-os. }\end{array}$} \\
\hline Sim (pouco intenso) & 8 & 16 \\
\hline Sim (intenso) & 4 & 8 \\
\hline Sim (muito intenso) & 9 & 18 \\
\hline Não & 29 & 58 \\
\hline
\end{tabular}




\section{Agradecimentos}

O presente trabalho foi realizado com apoio financeiro do Conselho Nacional de Desenvolvimento Científico e tecnológico (CNPq - Processo no 420040) e do DAAD - Serviço Alemão de Intercâmbio Acadêmico.

\section{Referências}

BELOJEVIC, G.; JAKOVLEVIC, B. \& ALEKSIC, O., 1997. Subjective reactions to traffic noise with regard to some personality traits. Environment International, 23: 221-226.

SMMA (Secretaria Municipal do Meio Ambiente - $\mathrm{Cu}-$ ritiba), 1995. Lei no 8.583. Dispõe sobre Ruídos Urbanos e Proteção do Bem-Estar e do Sossego Público. Curitiba: SMMA.

MASCHKE, C., 1999. Preventive medical limits for chronic traffic noise exposure. Acoustic, 85:448.

ZANNIN, P. H. T.; DINIZ, F. B. \& BARBOSA, W. A., 2002. Environmental noise pollution in the city of $\mathrm{Cu}-$ ritiba, Brasil. Applied Acoustics, 63:351-358.

ZANNIN, P. H. T.; DINIZ, F. B.; CALIXTO, A. \& BARBOSA, W. A., 2001. Environmental noise pollution in residential areas of the city of Curitiba. Acta Acustica, 87:625-662.

Recebido em 17 de outubro de 2001

Versão final reapresentada em 14 de agosto de 2002

Aprovado em 10 de outubro de 2002 